\title{
Surface modification of Trema orientalis wood biochar using natural coconut vinegar and its potential to remove aqueous calcium ions: column and batch studies
}

\author{
M.M. Udawatta, R.C.L. De Silva ${ }^{\dagger}$, D.S.M. De Silva \\ Department of Chemistry, University of Kelaniya, Kelaniya, Sri Lanka
}

Received October 18, 2021 Revised December 19, 2021 Accepted December 29, 2021

\begin{abstract}
Recent investigations have revealed the harmful health effects of elevated calcium levels in drinking water. Chemically activated biochar is the most popular option for low-cost cation adsorption. However, most of these chemicals are hardly available for rural communities, corrosive, and difficult to handle by unskilled personnel. This study aimed to determine the ability of natural coconut vinegar, a common mild acid, to activate Trema orientalis wood biochar pyrolyzed at $300^{\circ} \mathrm{C}(\mathrm{BC})$ as a facile, safe, and low-cost approach for aqueous calcium ion $\left(\mathrm{Ca}^{2+}\right)$ removal. Column tests showed a two-fold increase of $\mathrm{Ca}^{2+}$ adsorption capacity and a ten-fold increase of $\mathrm{Ca}^{2+}$ retaining capacity of $\mathrm{BC}$ after activation with vinegar. The isotherm results were well correlated with the Langmuir model. The maximum Langmuir adsorption of the activated biochar (BC-A) was $9.96 \mathrm{mg} / \mathrm{g}$. $\mathrm{Ca}^{2+}$ amount was determined using flame photometry. EDX analysis showed that the O/C ratio of BC increased from 0.07 to 0.13 after activation. FTIR and wettability studies showed increased oxygenated functional groups on the BC-A surface. The authors suggest a possible acid-catalyzed hydration of the C-O-C bridges of the biochar, introducing new hydroxyl/carbonyl/ester/carboxylic/lactone groups to the biochar surface due to the vinegar activation, enhancing $\mathrm{Ca}^{2+}$ adsorption through chemisorption.
\end{abstract}

Keywords: Adsorption capacity, Adsorption isotherms, Biochar, Calcium, Coconut vinegar, Trema orientalis

\section{Introduction}

In most developing countries, untreated groundwater or surface water is the sole source of drinking water for many communities [1]. Higher $\mathrm{Ca}^{2+}$ levels are common in most untreated water sources worldwide [2]. Recent research has provided evidence that higher $\mathrm{Ca}^{2+}$ levels cause dangerous health effects when combined with other factors, such as fluorides in water. A detailed hydrogeochemical investigation revealed a significantly lower sodium to calcium ratio in areas with a prevalence of Chronic Kidney Disease of unknown etiology (CKDu) in Sri Lanka, suggesting that high $\mathrm{Ca}^{2+}$ activity aggravates the damage caused by fluoride, which results in possible lesions on tubular cells of the kidney tissue [3]. A recent study conducted using rats also supports this idea. In the latter study, hard water with high fluoride content resulted in acute tubular injury in the tested rats [4]. In addition, the number of CKDu patients recorded has had a marked positive relationship with the extent of ground water hardness in Sri Lanka [5]. A number of advanced technologies have been proposed to purify water with varying degrees of success, such as ion exchange, reverse osmosis, and electrochemical treatment [6, 7]. However, complicated procedures and high operational and maintenance costs restrict rural communities from benefitting from them. Hence, the need for a low-cost and facile domestic process to reduce $\mathrm{Ca}^{2+}$ in drinking water is identified to improve the health and living standards of low-income communities.

Over the last few decades, adsorption has emerged as one of the most popular, efficient, and convenient methods for low-cost water treatment. Carbonaceous adsorbents are commonly used for the removal of various pollutants from water because of their abundance and cost-effectiveness [8, 9]. Biochar characteristics depend
This is an Open Access article distributed under the terms of the Creative Commons Attribution Non-Commercial License (http://creativecommons.org/licenses/by-nc/3.0/) which permits unrestricted non-commercial use, distribution, and reproduction in any medium, provided the original work is properly cited. $\dagger$ Corresponding author

E-mail: russel@kln.ac.lk

Tel: +94 (0)112903271

ORCID: 0000-0003-4454-2939

Copyright (C) 2023 Korean Society of Environmental Engineers 
on the feedstock type and pyrolysis conditions [10]. Different modification methods are also used to obtain biochar with the desired properties $[11,12]$. Chemical activation was identified as the most effective method. The presence of oxygenated functional groups on the biochar surface increases the retention capacity of various cationic contaminants on the biochar, as the oxygenated functional groups become deprotonated and the surface complexation of cations is promoted [13]. Acid treatments introduce oxygenated functional groups on the biochar surface [14]. Studies have evaluated the efficiency of strong acids, such as nitric, sulfuric, potassium permanganate, and hydrogen peroxide, etc. [11, 12], and mild acids, such as phosphoric, citric, acetic, and tartaric [15-17], in activating raw biochar used in water purification. However, most of these chemicals are not readily available for rural communities. On top of this, they are expensive, corrosive, and difficult to handle by unskilled personnel.

Thus, the aim of this study was to determine the efficacy of natural coconut vinegar, a common mild acid, in activating low temperature-pyrolyzed $\left(300^{\circ} \mathrm{C}\right)$ Trema orientalis wood biochar to be used in $\mathrm{Ca}^{2+}$ removal for domestic water purification. Feedstock selection is another critical factor in biochar production, as the feedstock should be inexpensive and readily available. Trema orientalis is a shade tree with light wood, soft foliage, and a rapid growth rate. It is abundantly available in Africa and Asia. It has been used by villagers for years as a source of charcoal for firewood, gunpowder, and fireworks. It is also referred to as the "charcoal tree" [18]. Coconut vinegar is a common food additive produced from the fermentable sap of coconut blossoms, where the oxidation of ethanol into acetic acid occurs with no preservatives or chemicals added. Fresh coconut vinegar is $\sim 4 \%$ acetic acid solution in water (4 g acetic acid/100 $\mathrm{mL}$ vinegar) with an approximate $\mathrm{pH}$ value of 2.5. Several other studies have reported the ability of acetic acid-modified biochar to remove aqueous methylene blue and diclofenac $[15,17]$. However, to our knowledge, the ability to remove aqueous metal using acetic acid-modified wood biochar has not yet been established.

\section{Materials and Methods}

\subsection{Materials Preparation}

Trema orientalis wood was collected from three sites in the North Central Province of Sri Lanka. Air-dried composite samples of wood pieces were carbonized $\left(300^{\circ} \mathrm{C}, 2 \mathrm{~h}\right)$ in a domestic kiln to produce biochar. Carbonized material was washed with deionized water and dried in an oven $\left(80^{\circ} \mathrm{C}, 24 \mathrm{~h}\right)$. It was identified as BC. BC $(<0.5 \mathrm{~mm}$ ) was conveyed for surface modification with commercially available natural coconut vinegar (manufactured by C. D. De Fonseka and Sons (Pvt) Ltd., Sri Lanka). The BC samples were soaked in vinegar (biochar/vinegar, 1:2 v/v) for $24 \mathrm{~h}$, decanted, and dried in an oven $\left(120^{\circ} \mathrm{C}, 5 \mathrm{~h}\right)$. The samples were then washed with deionized water until the washings were clear and dried in an oven $\left(80^{\circ} \mathrm{C}, 12 \mathrm{~h}\right)$. The product was identified as BC-A.

\subsection{Biochar Characterization}

BC and BC-A (particle size 2.0-5.6 mm) were analyzed using scan- ning electron microscopy with energy dispersive X-ray spectroscopy (SEM-EDX; Hitachi SU6600, Japan). BC and BC-A (particle size $<0.5 \mathrm{~mm}$ ) were analyzed using fourier-transform infrared spectroscopy (FTIR; PerkinElmer Spectrum Two L160000A, USA) in the spectral range of $750 \mathrm{~cm}^{-1}$ to $2,000 \mathrm{~cm}^{-1}$. Combustion characteristics were studied using thermogravimetric analysis (TGA; TA SDT 650, USA) under argon gas with a flow of $50 \mathrm{~mL} / \mathrm{min}$ and a $10^{\circ} \mathrm{C} / \mathrm{min}$ ramp. The mass loss of the samples was represented as a function of temperature. Samples were given a hold time of $20 \mathrm{~min}$ at $105^{\circ} \mathrm{C}$ to allow surface water to release. The wettability of BC and BC-A were assessed by determining the contact angle of a water drop placed on the biochar surface. To determine the contact angle, deionized water droplets (30 $\mu \mathrm{L})$ were placed on the biochar surface. Profile photos of the water drops were captured using a digital microscope after one minute. Contact angles were measured using HiView software. Ten different water drops were analyzed for both $\mathrm{BC}$ and $\mathrm{BC}-\mathrm{A}$, and the range of contact angle measurements was recorded.

\subsection{Column Tests}

For column tests, both BC and BC-A (particle size 2.0-5.6 mm) were used. Laboratory-scale filter units were prepared with glass columns $2 \mathrm{~cm}$ in diameter. Cotton was used to plug the lower ends of the columns to prevent the samples from leaching out. Sample materials were packed into separate columns and soaked in deionized water for one hour. A rubber mesh was plugged at the top of the packing material to prevent the samples from floating. $\mathrm{Ca}^{2+}$ adsorption was examined by passing $10.00 \mathrm{~mL}$ portions of $\mathrm{Ca}^{2+}$ solution $(350 \mathrm{mg} / \mathrm{L}, \mathrm{pH}=6.2 \pm 0.3$ ) through the column at a rate of $0.05 \mathrm{~mL} / \mathrm{s}$. Each $10.00 \mathrm{~mL}$ effluent was collected and filtered through a $0.45 \mu \mathrm{m}$ membrane. Filtrates were analyzed for $\mathrm{Ca}^{2+}$ using a flame photometer (Jenway PFP7, UK). The process was continued until effluent $\mathrm{Ca}^{2+}$ concentration reached its specific influent $\mathrm{Ca}^{2+}$ concentration. This was identified as the breakthrough point. After the breakthrough point, $\mathrm{Ca}^{2+}$ was desorbed from the column with $10.00 \mathrm{~mL}$ portions of deionized water $(0.05 \mathrm{~mL} / \mathrm{s})$. Effluents $(10.00 \mathrm{~mL})$ were collected and analyzed for $\mathrm{Ca}^{2+}$ using a flame photometer until effluent $\mathrm{Ca}^{2+}$ content was not detectable (LOD $=1 \mathrm{mg} / \mathrm{L}$ ). A plot of the $\mathrm{Ca}^{2+}$ concentration of the effluent versus effluent volume was used to calculate the $\mathrm{Ca}^{2+}$ amount adsorbed to the column and the $\mathrm{Ca}^{2+}$ amount desorbed from the

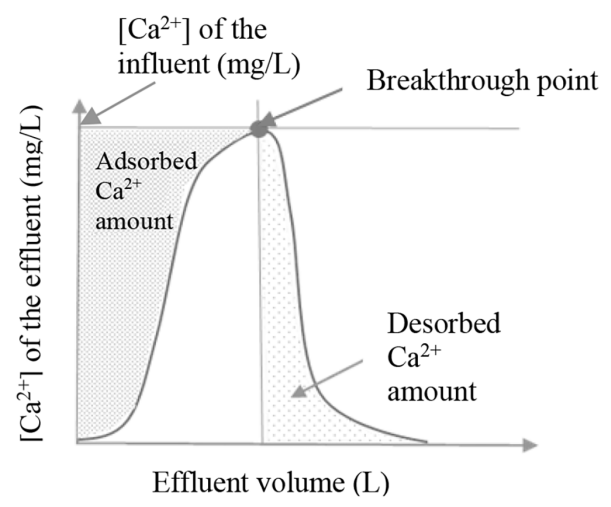

Fig. 1. Diagram of a plot of effluent $\mathrm{Ca}^{2+}$ concentration vseffluent volume. 
saturated column. This is shown in the diagram in Fig. 1. By subtracting desorbed $\mathrm{Ca}^{2+}$ amount from the adsorbed $\mathrm{Ca}^{2+}$ amount, retained $\mathrm{Ca}^{2+}$ amount in the column was calculated. Adsorption and desorption studies were carried out for both BC and BC-A samples in triplicate.

\subsection{Adsorption Equilibrium Studies}

Batch experiments were carried out using BC-A samples (particle size $<0.5 \mathrm{~mm}$ ). To determine the effect of contact time on adsorption, samples (0.10 g) were added to a series of $200 \mathrm{~mL}$ Erlenmeyer flasks with the same initial $\mathrm{Ca}^{2+}$ concentration $(50 \mathrm{mg} / \mathrm{L}, 20.00$ $\mathrm{mL}, \mathrm{pH}=6.2 \pm 0.3$ ) and allowed to equilibrate in an orbital shaker at $120 \mathrm{rpm}$ for varying contact time periods ranging from one minute to three hours. To determine the effect of initial $\mathrm{Ca}^{2+}$ concentration, samples (0.10 g) were added to $200 \mathrm{~mL}$ Erlenmeyer flasks with a series of different initial $\mathrm{Ca}^{2+}$ concentrations $(20.00 \mathrm{~mL})$ ranging from 20 to $250 \mathrm{mg} / \mathrm{L}(\mathrm{pH}=6.2 \pm 0.3$ ) and allowed to equilibrate in an orbital shaker at $120 \mathrm{rpm}$ for one hour. The solutions were filtered through a $0.45 \mu \mathrm{m}$ membrane and analyzed for $\mathrm{Ca}^{2+}$ using a flame photometer.

\subsection{Sample Analysis}

Filtrates were analyzed using a flame photometer to determine $\mathrm{Ca}^{2+}$. All reagents used were analytical grade. Method validation was done with the atomic absorption spectrometer (AAS; analyticjena NOVAA 400P, Germany), and the results were found to be in an acceptable range (90-110\%).The adsorbed $\mathrm{Ca}^{2+}$ was calculated on a dry weight basis (mg/g).

\section{Results and Discussion}

\subsection{Pyrolysis Temperature Selection}

Trema orientalis wood was carbonized at $300^{\circ} \mathrm{C}$ to produce biochar in a domestic kiln. Devolatilization and carbonization of hemicellulose and cellulose in wood begin at temperatures in the ranges of $180-240^{\circ} \mathrm{C}$ and $230-310^{\circ} \mathrm{C}$, respectively. Decomposition of lignin starts at $160^{\circ} \mathrm{C}$. Hence, the lower margin for wood biochar production temperatures by slow pyrolysis is set at $300^{\circ} \mathrm{C}$. At temperatures beyond $400^{\circ} \mathrm{C}$ aromatization reactions predominate, and the carbon structure becomes more ordered and graphitized due to the in- creased temperature [19]. This leads to a higher surface area, but the resulting loss of surface functional groups is a disadvantage in the adsorption process [20]. A number of studies have provided evidence that low-temperature-pyrolyzed biochar have the best cation exchange capacities. Furthermore, higher temperatures also cause reduced yield and require higher energy consumption. Thus, the use of higher temperatures will offset the cost effectiveness of using biochar. In addition, high-temperature pyrolysis conditions are not easily accessible at the domestic level. Hence, for the present study, the biochar pyrolysis temperature was set as $300^{\circ} \mathrm{C}$.

\subsection{Biochar Characterization}

The SEM analysis of BC and BC-A (Fig. 2) showed the porous nature of biochar. The mild activation process used in this study did not result in significant changes in the porosity of the biochar. Most of the harsh activation processes utilizing strong acids/bases lead to partial destruction of the porous structure while causing a significant reduction of reactive surface area when conditions are not optimized [14, 17]. According to the EDX data, O/C ratios of $\mathrm{BC}$ and BC-A were recorded as 0.07 and 0.13 , respectively, exhibiting the increase of oxygenated functional groups on the biochar surface after the vinegar activation.

The FTIR-ATR spectra (Fig. 3) provide evidence to suggest the available functional groups on the biochar surface. The intensities of the bands at $1,213,1,370$, and $1,737 \mathrm{~cm}^{-1}$ were significantly increased in the BC-A spectrum compared to the BC spectrum. These bands can be assigned to phenolic C-O stretch, aromatic $\mathrm{C}-\mathrm{O}$ stretch/aliphatic $\mathrm{CH}_{3}$ deformation, and $\mathrm{C}=\mathrm{O}$ stretch vibrations of carboxylic/esters/carbonyl/lactone groups respectively [21, 22]. Moreover, the broad band at about $3,400 \mathrm{~cm}^{-1}$ represents the stretching vibrations of the $\mathrm{O}-\mathrm{H}$ groups of water/carboxylic acids/phenols/alcohols. These bands reflect the possible modification of the BC-A surface with carbonyl/esters/carboxylic/lactone groups and hydroxyl groups by vinegar activation. All other absorption peaks were similar in both spectra. Janu et al. [23] claimed that the weak band at $1,120 \mathrm{~cm}^{-1}$ corresponds to C-O-C stretching. Nanda et al. [22] outlined that the bands at 1,442, 1,612, 2,865, and 2,930 $\mathrm{cm}^{-1}$ can be attributed to aliphatic C-H stretching/alkane, C-H scissoring and bending, aromatic $\mathrm{C}=\mathrm{C}$ ring stretching and aliphatic $\mathrm{C}-\mathrm{H}$ stretching in $\mathrm{CH}_{2}$ groups and $\mathrm{CH}_{3}$ groups respectively. According to the FTIR spectral analysis, the authors suggest a possible acid-catalyzed mechanism for the hydration of the C-O-C bridges of cellulose and

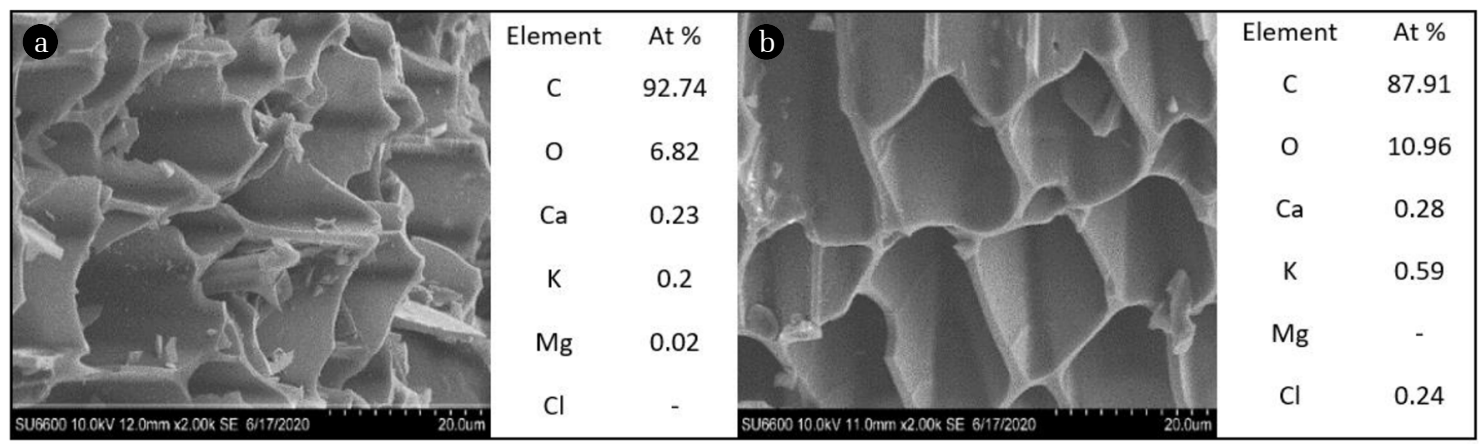

Fig. 2. SEM-EDX (a) BC and (b) BC-A at magnification 2000x. 
hemicellulose on the biochar surface, which introduces new hydroxyl and carbonyl/ester/carboxylic/lactone groups by vinegar activation.

The TGA data of BC and BC-A (Fig. 4) did not show any significant changes, showing that the vinegar treatment did not cause significant changes in the bulk structure of the biochar sample. However, BC-A shows a moderately lower weight loss up to $285^{\circ} \mathrm{C}$ and a slightly higher weight loss after $285^{\circ} \mathrm{C}$ than the $\mathrm{BC}$. As reported elsewhere, this can be due to the dehydration of physically adsorbed and bound moisture $\left(25-200^{\circ} \mathrm{C}\right)$ and the release of organic carbon $\left(200-500^{\circ} \mathrm{C}\right)$ from the biochar surface [24]. Thus, a higher weight loss of BC-A after $285{ }^{\circ} \mathrm{C}$ reveals the availability of more organic functional groups on the BC-A surface, resulting from the vinegar activation. The higher weight loss of $\mathrm{BC}$ up to $285^{\circ} \mathrm{C}$ could be due to the dehydration and dihydroxylation of loosely bound $\mathrm{OH}$ groups. According to Ek et al. [25], two adjacent hydroxyl groups release a water molecule during heating. In BC-A, loosely bound hydroxyl groups could be oxidized to carbonyl/ester/carboxylic/ lactone moieties following vinegar activation; hence, BC-A seems more stable at the beginning of heating.

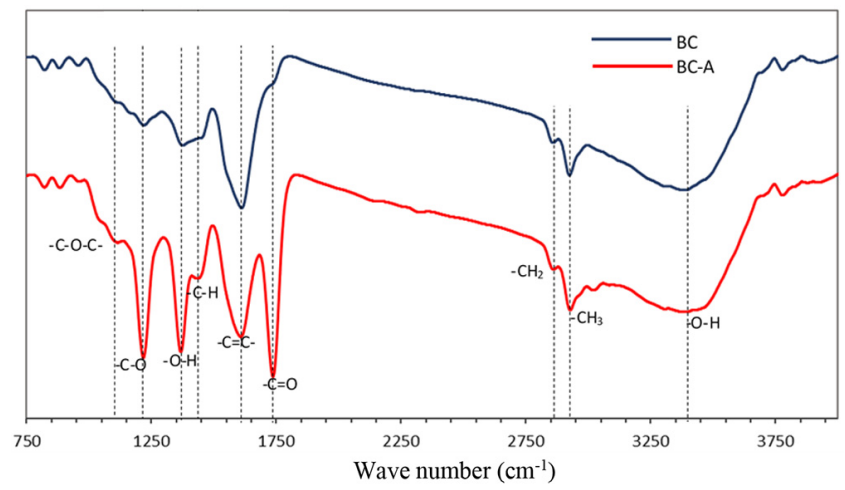

Fig. 3. FTIR-ATR spectra of $B C$ and $B C-A$.

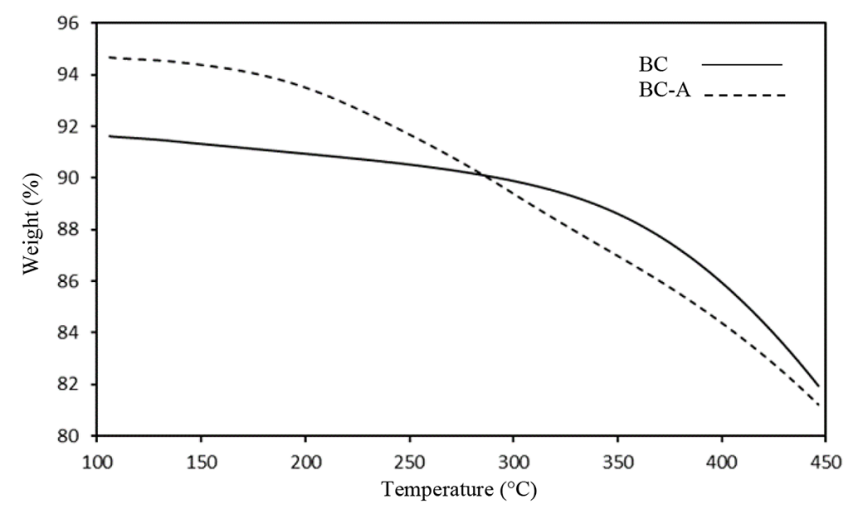

Fig. 4. TGA curves of $B C$ and $B C-A$.

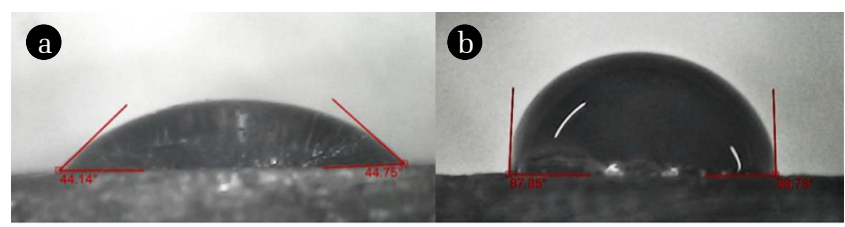

Fig. 5. Water droplets on (a) BC-A and (b) BC surface.
Fig. 5 shows water drops on the BC and BC-A surfaces. BC and BC-A show contact angles in the range of $61-115^{\circ}$ and $30-72^{\circ}$, respectively, which highlights the high affinity of BC-A towards water compared with BC. This can be attributed to the increased number of oxygenated functional groups on the BC-A surface. Surface functional groups directly affect the wettability properties of biochar, as polar or oxygenated functional groups on the biochar surface increase the hydrophilicity of biochar, which results in the formation of electrostatic interactions and hydrogen bonds with water [26].

\subsection{Column Tests}

The $\mathrm{Ca}^{2+}$ adsorption capacities of BC and BC-A ranged from 3.25$4.38 \mathrm{mg} / \mathrm{g}$ and 7.38-8.75 mg/g respectively, while the $\mathrm{Ca}^{2+}$ retaining capacities of the same samples ranged from $0.05-0.50 \mathrm{mg} / \mathrm{g}$ and 1.88-3.88 mg/g. The average $\mathrm{Ca}^{2+}$ adsorption capacities of $\mathrm{BC}$ and BC-A were $3.83 \pm 0.56 \mathrm{mg} / \mathrm{g}$ and $8.13 \pm 0.70 \mathrm{mg} / \mathrm{g}$, while the average $\mathrm{Ca}^{2+}$ retaining capacities of $\mathrm{BC}$ and BC-A were $0.27 \pm 0.23 \mathrm{mg} / \mathrm{g}$ and $2.67 \pm 1.06 \mathrm{mg} / \mathrm{g}$. According to the results, BC-A showed a two-fold increase in $\mathrm{Ca}^{2+}$ adsorption capacity and a ten-fold increase in $\mathrm{Ca}^{2+}$ retaining capacity due to activation. This significantly enhanced retaining capacity denotes the strong binding of the metal to the biochar, which did not wash off at the desorption step, suggesting chemisorption of the $\mathrm{Ca}^{2+}$.

\subsection{Adsorption Equilibrium Studies}

The correlation of adsorption data with theoretical or empirical equations can be used to gain further insight into the adsorption behavior of the adsorbent with the adsorbate. Batch experiments showed remarkably fast kinetics for the $\mathrm{Ca}^{2+}$ adsorption. About $90 \%$ of the adsorption was completed within the first three minutes. This stage may be due to the abundant number of available binding sites on the BC-A surface. Equilibrium was reached after seven minutes. The results were fitted to both pseudo-first-order (Eq. (1)) and pseudo-second-order (Eq. (2)) models,

$$
\begin{gathered}
\ln \left(q_{e}-q_{t}\right)=\ln q_{e}-k_{1} t \\
\frac{t}{q_{t}}=\frac{1}{k_{2} q_{e}^{2}}+\frac{t}{q_{e}}
\end{gathered}
$$

where $\mathrm{t}$ is the contact time (min), $\mathrm{q}_{\mathrm{e}}$ is the amount of $\mathrm{Ca}^{2+}$ adsorbed at equilibrium (mg/g), $\mathrm{q}_{\mathrm{t}}$ is the amount adsorbed $(\mathrm{mg} / \mathrm{g}$ ) at time $\mathrm{t}$, and $\mathrm{k}_{1}\left(\mathrm{~min}^{-1}\right)$ and $\mathrm{k}_{2}$ are rate constants $(\mathrm{g} / \mathrm{mg} \mathrm{min}) . \mathrm{R}^{2}$ values for the first-order and second-order models were 0.9238 and 0.9965 , respectively (Fig. 6). The results were well aligned with the pseudo second-order model, indicating possible chemisorption in the rate controlling step of the $\mathrm{Ca}^{2+}$ adsorption mechanism onto the activated biochar surface. This is also consistent with the rapid adsorption observed.

It was also found that $\mathrm{q}_{\mathrm{e}}$ increased with increasing initial $\mathrm{Ca}^{2+}$ concentrations $\left(\mathrm{C}_{0}\right)$, while the percentage $\mathrm{Ca}^{2+}$ removal from the solution decreased with increasing $\mathrm{C}_{0}$ (Fig. 7). Further, after a certain $\mathrm{C}_{o}$ value, adsorbed $\mathrm{Ca}^{2+}$ amount remained constant due to the surface saturation of the adsorbent. At low adsorbate concentrations, plenty of active adsorption sites are available; hence, adsorption 

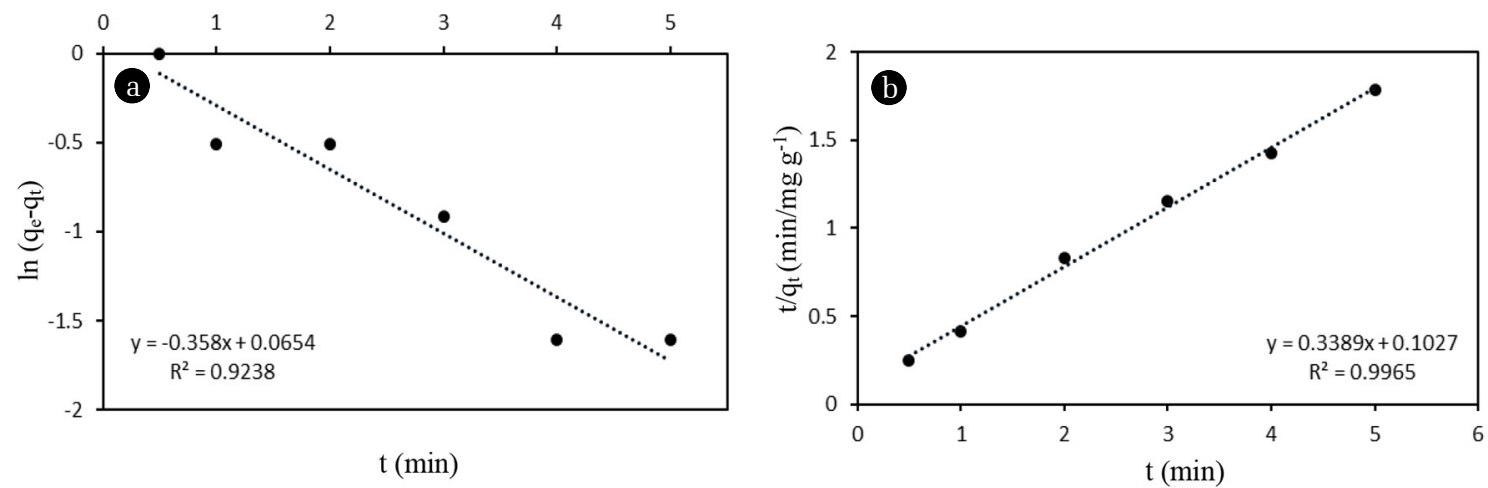

Fig. 6. Linear (a) pseudo first order and (b) pseudo second order models of adsorption kinetics. $\left(25^{\circ} \mathrm{C}, \mathrm{pH} 6.2 \pm 0.3,50 \mathrm{mg} / \mathrm{L}\right)$

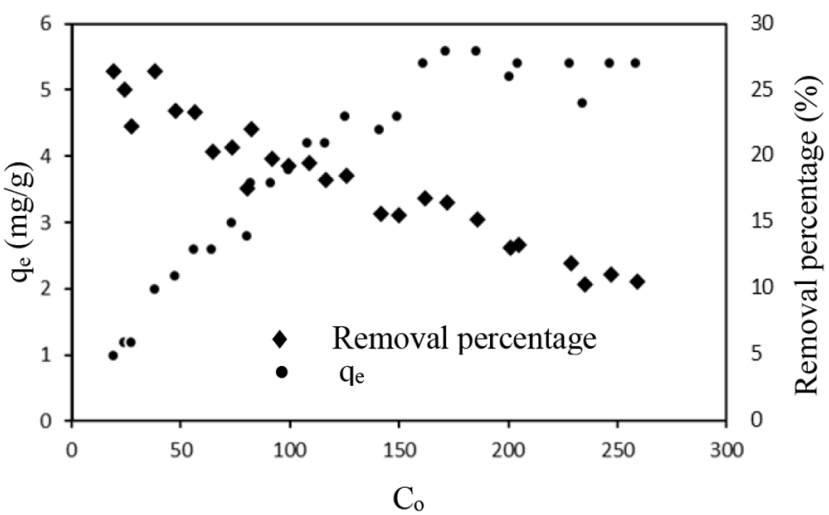

Fig. 7. Effect of initial $\mathrm{Ca}^{2+}$ concentration $(\mathrm{Co})$ on the adsorption. $\left(25^{\circ} \mathrm{C}\right.$, $\mathrm{pH}$ 6.2 \pm 0.3 , Dose: $0.1 \mathrm{~g} / 20 \mathrm{~mL}$ )

could be a monolayer, regardless of the adsorption mechanism. Many researchers have tended to focus on only low adsorbate concentrations to model adsorption isotherms, which in many instances misleads the interpretations of adsorption behavior [27, 28]. Adsorption equilibrium data were tested on the Langmuir, Freundlich, Temkin, and Dubinin Radushkevish isotherm models to understand the $\mathrm{Ca}^{2+}$ removal mechanism (Fig. 8). The Langmuir isotherm model is explained based on two major assumptions: the adsorbent surface is homogenous with uniformly distributed active sites, and the adsorption process continues only to form a monolayer. In this study, a derivative of the Langmuir model was used (Eq. (3)),

$$
1 / q_{e}=1 / q_{m}+1 / b q_{m} C_{e}
$$

where $\mathrm{q}_{\mathrm{m}}(\mathrm{mg} / \mathrm{g})$ is the maximum adsorption per unit mass of the adsorbent, $b$ is the Langmuir constant, and $C_{e}(m g / L)$ is the concentration of the adsorbate in the solution at equilibrium [28]. The Freundlich isotherm model explains adsorption onto the surface of a solid, assuming heterogeneous and multilayer adsorption. In this study, the following equation Eq. (4) was used, where $K_{F}$ is the Freundlich equilibrium constant and $n$ is an empirical constant [29].

$$
\ln q_{e}=\ln K_{F}+\frac{1}{n} \ln C_{e}
$$

The Temkin isotherm model assumes that adsorption energy decreases linearly with surface coverage. It is expressed by the following equation Eq. (5),

$$
q_{e}=\frac{R T}{b} \ln \left(A C_{e}\right)
$$

where $\mathrm{R}$ is the universal gas constant, $\mathrm{T}$ is the absolute temperature, $\mathrm{b}(\mathrm{J} / \mathrm{mol})$ is the heat of adsorption, and $\mathrm{A}(\mathrm{L} / \mathrm{mg})$ is the binding constant [30]. The Dubinin-Radushkevich model deals with sorption onto the porous structure of the sorbent, assuming that the adsorption has a multilayer character, involves Van der Waals forces, and is available for physical adsorption processes. It is expressed as follows Eq. (6),

$$
\ln q_{e}=\ln q_{m}-B_{D R}\left[R T \ln \left(1+1 / C_{e}\right)\right]^{2}
$$

where $B_{D R}$ is the Dubinin-Radushkevich constant $\left(\mathrm{g}^{2} / \mathrm{kJ}^{2}\right)$. The energy of adsorption can be computed by the relationship Eq. (7) [30],

$$
E=\frac{1}{\sqrt{2 B_{D R}}}
$$

The Langmuir adsorption model was found to have the best fit with the obtained results, followed by the Freundlich model. The $R^{2}$ values for the Langmuir and Freundlich models were 0.9775 and 0.9729 , respectively, close to 1.0 (Fig. 8). According to the Langmuir model, $\mathrm{q}_{\mathrm{m}}$ was calculated as $9.96 \mathrm{mg} / \mathrm{g}$. The Langmuir constant b was calculated as $0.0076 \mathrm{~L} / \mathrm{mg}$, indicating favorable adsorption. Further, the equilibrium constant of the adsorption $\mathrm{K}_{\mathrm{eq}}$ and the Gibbs free energy change of the adsorption $\Delta \mathrm{G}$ were calculated using the following equations (Eq. (8), (9)), where $M_{A}$ is the molar mass of the adsorbate [31].

$$
\begin{gathered}
K_{e q}=b M_{A} \\
\Delta G=-R T \ln K_{e q}
\end{gathered}
$$

The $\Delta \mathrm{G}$ for the adsorption was $-14.33 \mathrm{~kJ} / \mathrm{mol}$. The negative value of the $\Delta \mathrm{G}$ confirms the feasibility and the spontaneous nature of adsorption.

The intermolecular forces are listed here in order of decreasing strength: ionic $>$ ion-dipole $>$ dipole-dipole $>$ Van der Waal's 

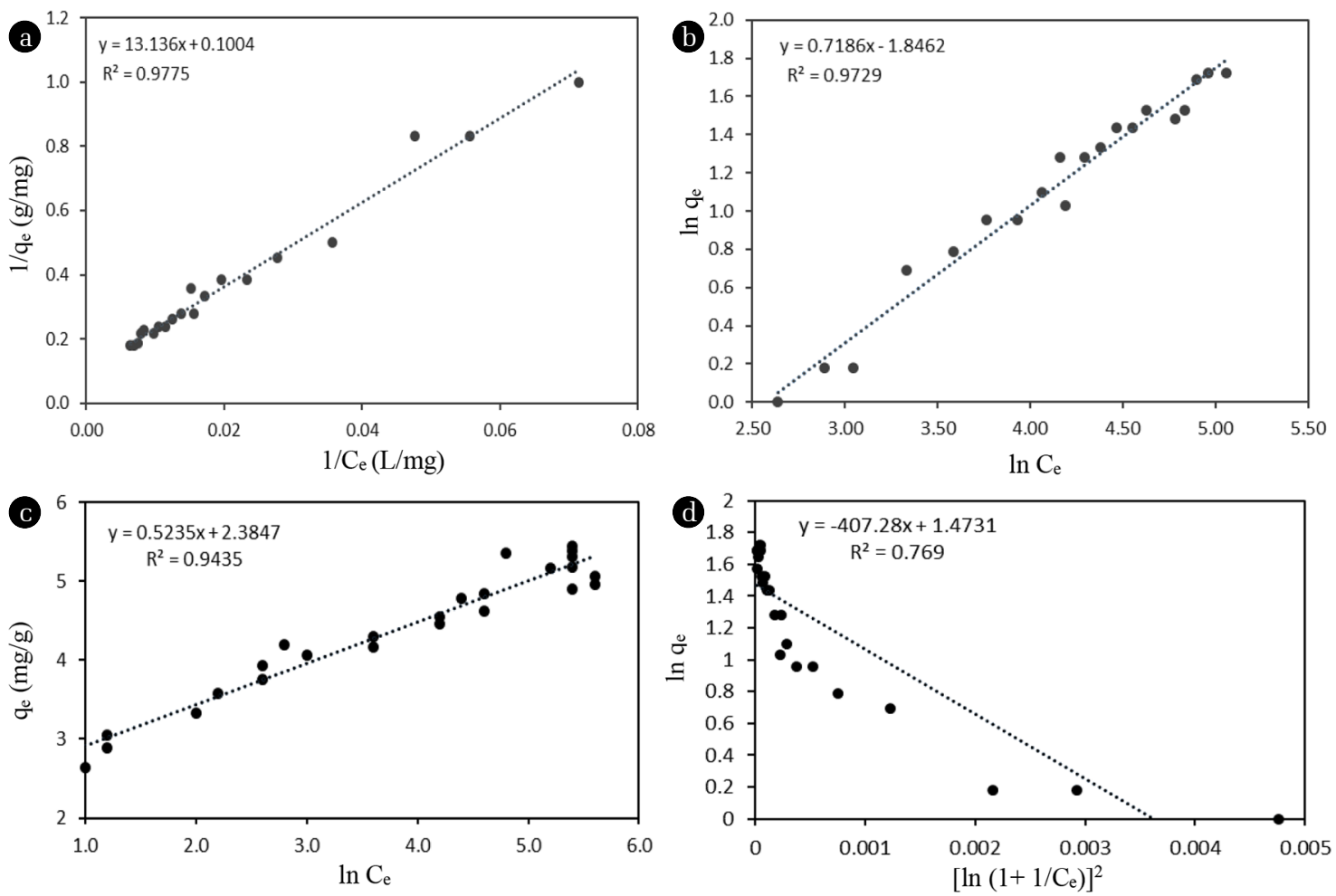

Fig. 8. Linear (a) Langmuir (b) Freundlich (c) Temkin (d) Dubinin - Radushkevich isotherm models $\left(25^{\circ} \mathrm{C}, \mathrm{pH} 6.2 \pm 0.3, \mathrm{Dose}: 0.1 \mathrm{~g} / 20 \mathrm{~mL}\right)$

forces. Thus, to be adsorbed onto an adsorbent, the metal ions need to overcome their hydration enthalpy. This is viable only when the metal has a higher affinity toward the active sites of the adsorbent than toward water. Thus, it is logical that the aqueous metal adsorption mechanism should be chemisorption through ion exchange. In physisorption (multilayer formation), Van der Waal's forces are the main attractive forces, which cannot feasibly overcome the stronger ion-dipole bonds from a thermodynamic standpoint. Generally, $\Delta \mathrm{G}$ values in the range of 0 to $-20 \mathrm{~kJ} / \mathrm{mol}$ denote physisorption, while values in the range of -80 to -400 $\mathrm{kJ} / \mathrm{mol}$ denote chemisorption [32]. However, the net change in the enthalpy appears to be small from isotherm calculations due to strong water-metal ion interactions. This is observed in almost all studies investigating metal removal from aqueous mediums through adsorption. This has resulted in misinterpretation in many works reported elsewhere [33-36] claiming the adsorption to be physisorption due to the low adsorption enthalpy $\Delta \mathrm{H}$ and low $\Delta \mathrm{G}$ observed. However, in this study, the authors suggest that the $\Delta \mathrm{G}$ of the bond breaking between metal ions and their hydration spheres should be a large positive value $\left(\Delta \mathrm{G}_{1}\right)$ and the $\Delta \mathrm{G}$ of the metal adsorption on the adsorbent (chemisorption) should be a larger negative value $\left(\Delta \mathrm{G}_{2}\right)$. Thus, the $\Delta \mathrm{G}$ obtained is the difference between the two $\Delta \mathrm{G}$ values $\left(\Delta \mathrm{G}_{2}-\Delta \mathrm{G}_{1}\right)$. Therefore, it was recorded as a small negative value.

For the Freundlich isotherm model, the Freundlich constants $\mathrm{K}_{\mathrm{F}}$ and $\mathrm{n}$, which correspond to the adsorption capacity and adsorption intensity, were calculated as $6.34 \mathrm{mg} / \mathrm{g}$ and $1.3916 \mathrm{~L} / \mathrm{mg}$, respectively. The Freundlich isotherm model describes adsorption on heterogeneous surfaces with varying adsorption energies that are not restricted to monolayer adsorption. The Freundlich constant $\mathrm{n}$ is a value between 1 and 10 that indicates favorable adsorption. Higher values imply stronger interactions between the adsorbent and the adsorbate, and $\mathrm{n}=1$ indicates linear adsorption with identical adsorption energies for all active sites. Previous studies have reported that when $\mathrm{n}=1$, adsorption is linear; when $\mathrm{n}<$ 1 , adsorption occurs through a chemical process; and when $\mathrm{n}>$ 1 adsorption occurs through a physical process [37-40] in aqueous metal adsorption. For cases where $n>1$, we have different interpretations, and we attribute this to the distribution of surface sites or any factors that cause a decrease in adsorbent-adsorbate interaction with increasing surface density. This was attributed to the fact that $\mathrm{Ca}^{2+}$ surface adsorption does not form a monolayer with single-site adsorption but forms one with two nearby adsorption sites to compensate for the +2 charge of $\mathrm{Ca}^{2+}$ [41]. The abandoned singly active sites scattered over the adsorbent could also be slightly occupied by hanging metal ions by compensating for only one positive charge of $\mathrm{Ca}^{2+}$ at higher concentrations. The experimental data were also well fitted to the Temkin equilibrium model $\left(\mathrm{R}^{2}\right.$ $=0.9435$ ), indicating that $\mathrm{Ca}^{2+}$ adsorption onto biochar could be a chemisorption process. The Dubinin-Raduskevich model is applied to deduce the heterogeneity of the surface energies of adsorption and to investigate the effect of adsorbent porosity on adsorption. The data obtained were not well correlated with the Dubinin-Raduskevich model $\left(\mathrm{R}^{2}=0.769\right)$. Values of $\mathrm{E}<8 \mathrm{~kJ} / \mathrm{g}$ indicate a physical adsorption process [30]. The calculated $\mathrm{E}$ value for the adsorption was found to be $87 \mathrm{~kJ} / \mathrm{g}$, indicating that the adsorption mechanism was not physisorption. Hence, considering the above model fittings, the adsorption mechanism is assumed 
to be a heterogeneous chemisorption process.

The maximum monolayer $\mathrm{Ca}^{2+}$ adsorption capacities $\left(\mathrm{q}_{\mathrm{m}}\right)$ of several modified adsorbents have been investigated by previous studies: $\mathrm{q}_{\mathrm{m}}=14.72 \mathrm{mg} / \mathrm{g}$ for sugarcane bagasse modified with tartaric acid [42], $\mathrm{q}_{\mathrm{m}}=27.64 \mathrm{mg} / \mathrm{g}$ for elephant foot yam skin modified with hydrochloric acid [43] and $\mathrm{q}_{\mathrm{m}}=15.6 \mathrm{mg} / \mathrm{g}$ for mercerized cellulose modified with ethylene diamine tetra acetic dianhydride (EDTAD) [44]. Although the above activation methods exhibit slightly increased adsorption capacities of $\mathrm{Ca}^{2+}$ ions, the studies used expensive and corrosive chemicals to modify biochar, which are not accessible to rural communities. The significance of the present study is that the activating agent, natural coconut vinegar, is a common mild acid that is safe to handle. The authors suggest that it will be beneficial to focus further research on this matter to discover more natural agents that can activate biochar.

\section{Conclusions}

This study attempted to modify Trema orientalis wood biochar pyrolyzed at $300^{\circ} \mathrm{C}$ with natural coconut vinegar using a facile process to increase its aqueous $\mathrm{Ca}^{2+}$ adsorption capacity. Data obtained from surface characterization techniques (EDX, FTIR, and wettability studies) and TGA suggest that vinegar activation remarkably increased the amount of surface oxygenated functional groups of the biochar. FTIR showed the increase of carbonyl/esters/carboxylic/lactone and hydroxyl groups on the biochar surface. According to EDX analysis, O/C ratios of BC and BC-A were 0.07 and 0.13 , respectively, which corresponds to a two-fold increase. Data from equilibrium studies showed that adsorption isotherms favored the Langmuir and Freundlich models, and the adsorption process could be explained by pseudo second-order kinetics. Hence, the adsorption mechanism is assumed to be a heterogeneous chemisorption process with surface complexation of $\mathrm{Ca}^{2+}$ with deprotonated oxygenated functional groups through ion exchange. The thermodynamic parameter $\Delta \mathrm{G}$ of the adsorption $(-14.33 \mathrm{~kJ} / \mathrm{mol})$ also confirmed the spontaneous nature of the chemisorption process. According to the SEM images, the porosity of the biochar remained unchanged after activation. Maximum $\mathrm{Ca}^{2+}$ adsorption capacities of activated biochar were recorded as $8.13 \pm 0.70 \mathrm{mg} / \mathrm{g}$ with column tests (particle size $2.0-5.6 \mathrm{~mm}$ ) and $9.96 \mathrm{mg} / \mathrm{g}$ with the Langmuir isotherm model (particle size $<0.5$ $\mathrm{mm}$ ) using batch study results. Column tests showed a two-fold increase in $\mathrm{Ca}^{2+}$ adsorption capacity and a ten-fold increase in $\mathrm{Ca}^{2+}$ retaining capacity after vinegar activation. Increased oxygenated functional groups on the activated biochar may have caused the enhanced $\mathrm{Ca}^{2+}$ adsorption capacity, as deprotonated oxygenated functional groups promote complexation with cations through ion exchange. Maximum monolayer $\mathrm{Ca}^{2+}$ adsorption capacities $\left(\mathrm{q}_{\mathrm{m}}\right)$ of chemically modified carbonaceous adsorbents recorded in the literature exhibit slightly higher $\mathrm{Ca}^{2+}$ adsorption capacities compared to this study. However, in these studies, expensive and corrosive chemicals were used to modify biochar, which are not accessible to rural communities. Furthermore, any remaining chemical residue makes it dangerous to use these chemically modified adsorbents for drinking water purification. The significance of the present study is that the activating agent, natural coconut vinegar, is a common mild acid that is safe to handle, and the activating process is facile and cost effective. This study concluded that natural coconut vinegar is a good alternative to harsh chemicals used in biochar activation. The authors suggest focusing further research on this matter to discover more commonly available natural agents that can activate biochar, which can be used more effectively in household water purification plants. Additionally, it is necessary to optimize filter bed parameters (column size, particle size, flow rate, etc.) on a large scale to achieve the best efficiency for vinegar-activated biochar in $\mathrm{Ca}^{2+}$ removal in household water treatment plants.

\section{Acknowledgment}

This work was supported by the University of Kelaniya, Sri Lanka under the research grant $\mathrm{RP} / 03 / 02 / 06 / 01 / 2020$.

\section{Conflict-of-Interest}

The authors have no conflicts of interest to declare that are relevant to the content of this article.

\section{Author Contributions}

M.M.U. (Postgraduate student) conducted all the experiments and prepared the original draft. R.C.L.D.S. (Senior Lecturer) supervision, funding acquisition, writing-review and editing. D.S.M.D.S. (Professor) supervision, writing-review and editing.

\section{References}

1. Progress on household drinking water, sanitation and hygiene 2000-2017: Special focus on inequalities [Internet]. New York: United Nations Children's Fund (UNICEF) and World Health Organization; 2019 [cited 15 January 2021]. Available from: http://www.ephttps://www.unicef.org/media/55276/file/ Progress\%20on\%20drinking\%20water,\%20sanitation\% 20and\%20hygiene\%202019\%20.pdf.

2. Awoyemi OM, Achudume AC, Okoya AA. The Physicochemical Quality of Groundwater in Relation to Surface Water Pollution in Majidun Area of Ikorodu, Lagos State, Nigeria. Am. J. Water Resour. 2014;2(5):126-133.

3. Chandrajith R, Dissanayake CB, Ariyarathna T, Herath HMJMK, Padmasiri JP. Dose-dependent Na and Ca in fluoride-rich drinking water-Another major cause of chronic renal failure in tropical arid regions. Sci. Total Environ. 2010;409:671-675.

4. Perera T, Ranasinghe S, Alles N, Waduge R. Experimental rat model for acute tubular injury induced by high water hardness and high water fluoride: efficacy of primary preventive intervention by distilled water administration. BMC Nephrol. 2020;21(1):103.

5. Paranagama PA. Potential link between ground water hardness, arsenic content and prevalence of CKDu. In: Symposium on 
Chronic Kidney Disease of Uncertain etiology (CKDU)-A Scientific Basis for Future Action; 10 December 2013; Colombo. p. 19-26.

6. Sharma S, Bhattacharya A. Drinking water contamination and treatment techniques. Appl. Water Sci. 2017;7:1043-1067.

7. Shannon MA, Bohn PW, Elimelech M, Georgiadis JG, Marin BJ, Mayes AM. Science and technology for water purification in the coming decades. Nature 2008;452:301-310.

8. Gwenzi W, Chaukura N, Noubactep C, Mukome FND. Biochar-Based Water Treatment as a Potential Low-cost and Sustainable Technology for Clean Water Provision. J. Environ. Manage. 2017;197:732-749.

9. Chan CCV, Lari K, Soulsbury K. An intermittently operated biochar filter to remove chemical contaminants from drinking water. Int. J. Environ. Sci. Technol. 2020;17:3119-3130.

10. Tomczyk A, Sokołowska Z, Boguta P. Biochar physicochemical properties: pyrolysis temperature and feedstock kind effects. Rev. Environ. Sci. Biotechnol. 2020;19:191-215.

11. Sajjadi B, Zubatiuk T, Leszczynska D, Leszczynski J, Chen WY. Chemical activation of biochar for energy and environmental applications: a comprehensive review. Rev. Chem. Eng. 2018;35(7):777-815.

12. Vijayaraghavan K. Recent advancements in biochar preparation, feed stocks, modification, characterization and future applications. Environ. Technol. Rev. 2019;8(1):47-64.

13. Peiris C, Nayanathara O, Navarathna CM, et al. The influence of three acid modifications on the physicochemical characteristics of tea-waste biochar pyrolyzed at different temperatures: a comparative study. RSC Adv. 2019;9:17612-17622.

14. Khandaker S, Kuba T, Toyohara Y, Kamida S, Uchikawa Y. Development of ion-exchange properties of bamboo charcoal modified with concentrated nitric acid. IOP Conf Ser: Earth Environ. Sci. 2017;82(1):012002.

15. Lonappan L, Liu Y, Rouissi T, Brar SK, Surampalli RY. Development of biochar-based green functional materials using organic acids for environmental applications. J. Clean. Prod. 2020;244:118841.

16. Sun L, Chen D, Wan S, Yu Z. Performance, kinetics, and equilibrium of methylene blue adsorption on biochar derived from eucalyptus saw dust modified with citric, tartaric and acetic acids. Bioresour. Technol. 2015;198:300-308.

17. Xu Y, Liu Y, Liu S, et al. Enhanced adsorption of methylene blue by citric acid modification of biochar derived from water hyacinth (Eichornia crassipes). Environ. Sci. Pollut. Res. 2016;23: 23606-23618.

18. K Fern. Trema orientalis - (L.) Blume [Internet]. Plants for a Future; 1997 [cited 10 January 2021]. Available from: https:// pfaf.org/user/Plant.aspx?LatinName=Trema+orientalis

19. Wiedemeier DB, Abiven S, Hockaday WC, Keiluweit, M, Kleber M, Masiello CA, McBeath AV, Nico PS, Pyle LA, Schneider MP. Org. Geochem. 2015;78:135-143.

20. Shen YS, Wang SL, Tzou YM, Yan YY, Kuan WH. Removal of hexavalent Cr by coconut coir and derived chars the effect of surface functionality. Bioresour. Technol. 2012;104:165-172.

21. Parikh SJ, Goyne KW, Margenot AJ, Mukome FND, Calderón FJ. Soil Chemical Insights Provided through Vibrational Spectroscopy. US: USDA-ARS/UNL Faculty; 2014. p. 51.
22. Nanda S, Mohanty P, Pant KK, Naik S, Kozinski JA, Dalai AK. Characterization of North American Lignocellulosic Biomass and Biochars in Terms of their Candidacy for Alternate Renewable Fuels. Bioenerg. Res. 2013;6:663-677.

23. Janu R, Mrlik V, Ribitsch D, et al. Biochar surface functional groups as affected by biomass feedstock, biochar composition and pyrolysis temperature. Carbon Resour. Convers. 2021;4:36-46.

24. Singh B, Arbestain MC, Lehmann J. Biochar: A guide to analytical methods. New York: Taylor and Francis Group; 2017. p. 285.

25. Das O, Hedenqvist MS. Wettability Properties of Biochar Added Wood/Polypropylene Composites. Academ. J. Polym. Sci. 2018;1(4):66-69.

26. Ek S, Root A, Peussa M, Niinisto L. Determination of the hydroxyl group content in silica by thermogravimetry and a comparison with 1H MAS NMR results. Thermochimica. Acta. 2001;379(1): 201-212.

27. Ibrahim WMHW, Amini MHM, Sulaiman NS, Kadir WRAK. Powdered activated carbon prepared from Leucaena leucocephala biomass for cadmium removal in water purification process. Arab. J. Basic Appl. Sci. 2019;26(1):30-40.

28. Rahim ARA, Mohsin HM, Thanabalan M, et al. Effective carbonaceous desiccated coconut waste adsorbent for application of heavy metal uptakes by adsorption: Equilibrium, kinetic and thermodynamics analysis. Biomass Bioenergy 2020;142:105805.

29. Kuang W, Tana Y, Fu L. Adsorption kinetics and adsorption isotherm studies of chromium from aqueous solutions by HPAM-chitosan gel beads. Desalin. Water Treat. 2012;45:222228.

30. Ahmad M, Lee SS, Rajapaksha AU, et al. Trichloroethylene adsorption by pine needle biochars produced at various pyrolysis temperatures. Bioresour. Technol. 2013;143:615-622.

31. Ghosal PS, Gupta AK. Determination of thermodynamic parameters from Langmuir isotherm constant-revisited. J. Mol. Liq. 2016;225:137-146.

32. Húmpola PD, Odetti HS, Fertitta AE, Vicente JL. Thermodynamic analysis of adsorption models of phenol in liquid phase on different activated carbons. J. Chil. Chem. Soc. 2013;58(1):1541-1544.

33. Argun ME, Dursun S. A new approach to modification of natural adsorbent for heavy metal adsorption. Bioresour. Technol. 2008;99(7):2516-2527.

34. Hu X, Song J, Wang H, et al. Adsorption of $\mathrm{Cr}(\mathrm{VI})$ and $\mathrm{Cu}(\mathrm{II})$ from aqueous solutions by biochar derived from Chaenomeles sinensis seed. Water Sci. Technol. 2019;80(12):2260-2272.

35. Khan TA, Mukhlif AA, Khan EA. Uptake of $\mathrm{Cu}^{2+}$ and $\mathrm{Zn}^{2+}$ from simulated wastewater using muskmelon peel biochar: Isotherm and kinetic studies. Egypt. J. Basic Appl. Sci. 2017;4(3): 236-248.

36. Taghlidabad RH, Sepehr E, Khodaverdiloo H, Samadi A, Sadaghiani MHR. Characterization of cadmium adsorption on two cost-effective biochars for water treatment. Arab. J. Geosci. 2020;13:448.

37. Ajenifuja E, Ajao JA, Ajayi EOB. Adsorption isotherm studies of $\mathrm{Cu}$ (II) and Co (II) in high concentration aqueous solutions on photocatalytically modified diatomaceous ceramic adsorbents. Appl. Water Sci. 2017;7:3793-3801.

38. Annah L, Astrini N. Isotherm adsorption studies of $\mathrm{Ni}(\mathrm{II})$ ion 
removal from aqueous solutions by modified carboxymethyl cellulose hydrogel. IOP Conf Ser: Earth Environ. Sci. 2018;160: 012017.

39. Desta MB. Batch Sorption Experiments: Langmuir and Freundlich Isotherm Studies for the Adsorption of Textile Metal Ions onto Teff Straw (Eragrostis tef ) Agricultural Waste. J. Thermodyn. 2013;2013:375830.

40. Senani GMA, Fowzan FFA. Study on Adsorption of $\mathrm{Cu}$ and Ba from Aqueous Solutions Using Nanoparticles of Origanum (OR) and Lavandula (LV). Bioinorg. Chem. Appl. 2018;3936178.

41. Parangi T, Wani B, Chudasama U. Kinetics, Thermodynamics and ion exchange characteristics of thorium phosphate: An inorganic ion exchanger. Indian J. Chem. 2014;53A(6):700-705.
42. Soliman EM, Ahmed SA, Fadl AA.Removal of calcium ions from aqueous solutions by sugar cane bagasse modified with carboxylic acids using microwave-assisted solvent-free synthesis. Desalination 2011;278(1-3):18-25.

43. Lestari A, Malik A, Ilmi MI, Sidiq M. Removal of calcium and magnesium ions from hard water using modified Amorphophallus campanulatus skin as a low cost adsorbent. In: $2^{\text {nd }}$ International Conference on Engineering and Technology for Sustainable Development; 2018;154:01020.

44. Jinior OK, Gurgel LVA, Gil LF. Removal of $\mathrm{Ca}(\mathrm{II})$ and $\mathrm{Mg}$ (II) from aqueous single metal solutions by mercerized cellulose and mercerized sugarcane bagasse grafted with EDTA dianhydride (EDTAD). Carbohydr. Polym. 2010;79(1):184-191. 